\title{
Display space color design
}

\author{
Xu Gong \\ (Guilin UniversIty Of Electronic Technology, 541004, Guilin, Guangxi, China)
}

\section{Keywords: display space color action}

\begin{abstract}
The color is the most direct, most likely to affect the design elements, the first impression to visitors enter the exhibition space, mainly through the building. For a color display space, color design is reasonable or not, and vision the psychological impact of differences on the audience greatly. This paper analyzes the color display space design in the psychological effect of, summed up several principles of color design.
\end{abstract}

\section{Introduction}

At present, various exhibitions, fairs, fairs, fairs and other activities frequently show China display space design has entered a period of rapid development period; exhibition industry has become a bright spot in China's economic growth, it is of a city economy plays a very important role.

Modern display design is a comprehensive discipline. All forms, materials, colors and lights in the space are responsible for the task of transmitting information.

On a display space, color design is reasonable or not, the visual and psychological impact on the audience. Because of great difference, color is the most direct, most likely to affect the design elements, the first impression of the viewer into the exhibition space, the space is mainly composed of color to create atmosphere around. Display space design excellent. Color can be used as a silent language, communicate with the viewer's mind, the author wants to convey the message of infection audience, so as to achieve a good display purposes.

\section{Display the psychological effect of color in space.}

The color itself does not have the effect of color emotion, different wavelengths in the human visual organ, through visual nerve to the brain, after thinking, and the memory of past experience, Lenovo, which formed a series of color psychological reactions.

Therefore, people face different colors will produce different psychological experience.

(1) Color temperature: the color can make people have a sense of temperature, people see the red, orange, yellow, warm, easy to think of the sun, flame like, feel warm, warm, prone to impulsive, emotional hot. See blue, green, gray and cool, think of snow and ice, marine and other objects has the reason, feel cold, calm feeling. Like the magic world of ice, the ice museum display space in this series, the main use of white, the three blue and gray color to create a cold world of ice and snow. Therefore, according to the type of display space, make full use of color temperature to shape display space atmosphere .

(2) Color weight: color can produce a sense of weight, color different relation to the severity of different relations, weight is generally based on the difference between the brightness of the high brightness color feeling light, relaxed, lively; low lightness color makes people feel heavy and dignified. If the same brightness. Low chroma than high chroma and feel heavy. The exhibition space would like to create a lively atmosphere, you need to use warm colors and high brightness color; if you want to create a calm atmosphere of the space, need to use cool color and lightness than low color to create a space atmosphere.

(3) The sense of color: the color can make people aware of the volume change, high brightness and warm colors seem large, with an inflated sense of lightness; low color and cool colors show the small scale, there is a sense of contraction. In the design of exhibition space, the use of wall bright colors than deep color looks the space area is bigger, the top surface of the use of bright colors than 
using deep color sensation space increased. Therefore, different display space, through the color shading of the space to create.

(4) Far and near colors: The distance of color sense is to color, brightness, purity, illusion and other area contrast caused. Red, orange and yellow and warm with a forward sense of impending, blue, green and other colors make people feel a sense of back, away from the color background. Progress has a great impact, and also. In addition, a large area of small area with a sense of progress. Therefore, in the design process of the exhibition space, when the choice of color should be based on different uses of exhibition space basis.

(5) Gorgeous colors and sense of simplicity: The color is gorgeous or plain, the largest and color association. Red, orange and other bright and bright yellow, the color gives the feeling of gorgeous, bright, brilliant blue, green and so on; cool is calm, simple, relatively simple to give people sense of purity. From the point of view, the higher the purity of color more gorgeous for example, the quiet blue, saturated blue, noble gorgeous peacock blue, sapphire blue gives a very gorgeous feeling, with the purity of color will be reduced, it is more simple, such as blue and grey. From the point of view of brightness, bright color contrast is lively, gorgeous, dark and deep tone to a person with stable, retention, A simple sense. Therefore, this kind of general Museum exhibition space, in order to create a calm atmosphere, deep space atmosphere, rigorous, generally do not use very gorgeous colors. This type of some of the opening ceremony of the ritual display space design, you need to use a bright color, outstanding auspicious gorgeous, space atmosphere happy.

\section{Display space color design principles}

In the design process of the exhibition space, high color design difficulty, the ultimate effect of the exhibition space and create an atmosphere of the show to play a very important role. To give full play to the role of color, to create a good atmosphere, mobilize the initiative participation of visitors, designers need to follow certain principles of color design.

(1) Unity

Exhibition design is a comprehensive art, is rich in content, involving a wide range of fields. In the design process, the designer should follow the overall design requirements, through the integration of the color relations, form a unified tone. The exhibition wall, exhibits, props, lighting should be considered in the overall color tone. The type, and to display space and function, mood and atmosphere to adapt, so as to enhance the whole exhibition space of art, to the audience to bring high-quality visual experience, to show the purpose of conveying information.

(2) Thematic

In the display space, the most important and most important thing is the exhibits. Therefore, color design should consider what kind of color to highlight the theme, foil the display atmosphere, highlight the exhibits

In the process of selecting the color, the designer should carefully analyze the display of the theme and content, and collocation and color according to the theme and content selection. For example, the design of Museum exhibition space, generally choose calm tone, it can not only create a quiet environment, but also highlight the exhibits, the viewer can better enjoy the exhibits.

(3) Rich

A display space, if you only use a color, then the whole space of the tone will be too monotonous, single, no change, dull and boring, it is difficult to produce artistic beauty. Different colors bring different feelings to people, people enter a space after the first color perception in the form. Therefore, in the design in the process of determining the main colors according to the objective nature, object to the exhibits, the color design, the color change in abundance based on the main tone.

Through the hue, brightness, purity, area, texture and other aspects of orderly, regular changes, and thus to promote the audience and customers in the display space to maintain a strong interest and continue to visit, the desire to buy.

(4) Rationality 
In the commercial exhibition space design, the use of color to be reasonable, complement each other, we must eliminate the use of color and exhibits is a serious conflict. In some commercial display space design, some designers in order to make the whole space appear out of the ordinary, highlight offbeat personality, a large amount of use of some irritating color in the interface and space furnishings although, can bring a strong visual impact, but the audience in this kind of space is easy to produce visual fatigue, to display the display effect is also very unfavorable. Therefore, in the design process of the exhibition space, must avoid using stimulus colors, reasonable use of color.

(5) Territoriality

Different ethnic groups in different regions, different cultural backgrounds and religious beliefs, there is a huge difference in the color usage. For example, we Chinese very love red, the Chinese Lunar New Year fireworks is red, give children gift money is wrapped with red, even the famous "Red Star" to describe, even the red red is named "red China". While in other countries, red is considered a symbol of blood and killing. Therefore, the process of exhibition space design, we must consider the different customs and habits, so that we can design a reasonable and popular, accept the exhibition space.

(6) In line with the audience preferences

Different types of exhibition space has a different audience, if you want to get a good display space display effect, need to study people's personality and hobbies. Such as the number of female products exhibition space, will generally choose soft, romantic colors to create a space, such as soft and dreamy pink, elegant and romantic purple. This is because most women all love the gentle and romantic visual experience and psychological experience. Some men in the special exhibition space, often with black, gray, blue color. These tough rational.

Therefore, the display space design process of color matching, should combine the audience group personality, hobbies and appreciation of the concept of reasonable design.

(7) Rational use of fashionable colors

Popular color refers to in a certain period of time by the masses widely loved. Color display space design is influenced by the popular trend, especially the commercial display space, the designer should make rational use of popular color, cater to consumer psychology, in order to win the favor of consumers, stimulate consumption. For example, this year's hot caramel color. Known as the darling of fashion, in addition to reveal high sense in the clothing, used to display space can not only create a warm, warm feeling, make whole space more prominent noble character.

\section{Conclusion}

The color has enriched our life and color will make our life more colorful. In the design of exhibition space, color as a silent language, affects to create exhibition atmosphere. Therefore, in the design of exhibition space, the design should pay attention to the color, make the color design better into the exhibition design, create a good atmosphere of space, mobilize the initiative participation of visitors, to complete the design of display space mission.

\section{References}

[1] Wang Yu, discussion on the application of color in exhibition space[J], fine arts grand view, 2012(12)

[2] Wang Qian, color application in exhibition space [J], modern decoration, 2013 (07) 